\title{
Thin Films of Substituted Polyanilines: Interactions with Biomolecular Systems
}

\author{
David Sarauli, ${ }^{1}$ Chenggang $X u,{ }^{2}$ Birgit Dietzel, ${ }^{3}$ Konstanze Stiba, ${ }^{4}$ Silke Leimkühler, ${ }^{4}$ Burkhard \\ Schulz, ${ }^{3}$ Fred Lisdat ${ }^{* 1}$ \\ E-mail: flisdat@th-wildau.de \\ ${ }^{1}$ Biosystems Technology, Wildau University of Applied Sciences, Bahnhofstr. 1, Wildau, D-15745 \\ Wildau, Germany \\ ${ }^{2}$ UP Transfer GmbH, Am Neuen Palais 10, D-14469 Potsdam \\ ${ }^{3}$ University of Potsdam, Institute for Physics and Astronomy, Karl-Liebknecht-Straße 24-25, D-14476 \\ Potsdam, Germany \\ ${ }^{4}$ University of Potsdam, Institute for Biochemistry and Biology, Department of Molecular Enzymology, \\ Karl-Liebknecht-Straße 24-25, D-14476 Potsdam, Germany
}

\begin{abstract}
Differently substituted polyaniline copolymes are shown to provide interfaces for the communication with biosystems. The various substitutions of the aromatic ring are influencing the conductivity properties of the polymer immobilized on electrode surfaces, and lead to a modified interaction with proteins and/or enzyme molecules. It is shown that an analytical signal chain starting from the substrate sulfite in solution via the enzyme sulfite oxidase and the redox protein cyt $c$ to the polymer can be constructed. The electron transfer is also shown without the use of an electric field. The enzymatic system induces redox switching between oxidized and reduced states of polymer, which can be visualized not only in solution, but also with a thin polymer film on electrodes.
\end{abstract}

Key words: thin polymer films, cytochrome c, sulfite oxidase, bioelectrocatalysis

\section{Introduction}

The organic nature of conductive, electroactive polymers, such as polyanilines, provides a good basis for the construction of electrodes that enables efficient communication with biosystems [1 and therein]. Particularly polyanilines have attracted great attention not only because of their electronic, electrochemical and optical properties as well as environmental and thermal stability, but also due to their capability to be rapidly and reversibly switched between different oxidation states.

\section{Results and Discussion}

In order to construct new types of interfaces for the biocatalytic reactions polyaniline copolymes containing 2-methoxyaniline-5-sulfonic or anthranilic acid and various ratios of aniline have been chemically synthesized and used to get polymer films on the surface of electrodes by simple adsorption from the organic solvent (DMSO). Furthermore, the redox protein cyt c has been investigated in solution as well as on the surface of polymer-modified electrodes. Since cyt $c$ is known to undergo efficient electron transfer with the enzyme sulfite oxidase (SO), we have used this enzyme for the investigation of the molecular switching between polyaniline redox states in the presence and in the absence of redox protein.

The results show that polymers (Scheme 1) are able to form thin stable films on gold wire and ITO electrode surfaces from DMSO solution, which is verified by cyclic voltammetry and UVVis spectroscopy. Such electrode modifications are not only suitable for the electrochemical conversion of the redox protein cyt $\mathrm{c}$ in solution, but also form an interface on which the redox protein can be immobilized efficiently in its electroactive form. However, the sulfonated copolymer (PMSA1) introduces the most suitable surface for the immobilization of cyt $\mathrm{c}$, here the determined electroactive amount $(\Gamma=$ $30-35 \mathrm{pmol} / \mathrm{cm}^{2}$ ) is higher than values obtained with flat electrodes [2] (Figure 1).

Furthermore, the polymer film provides a suitable surface for the construction of an analytical signal chain starting from sulfite in solution via sulfite oxidase and cyt $c$ to the polymer (Figure 2). The electron transfer can also be achieved without the use of an electric 

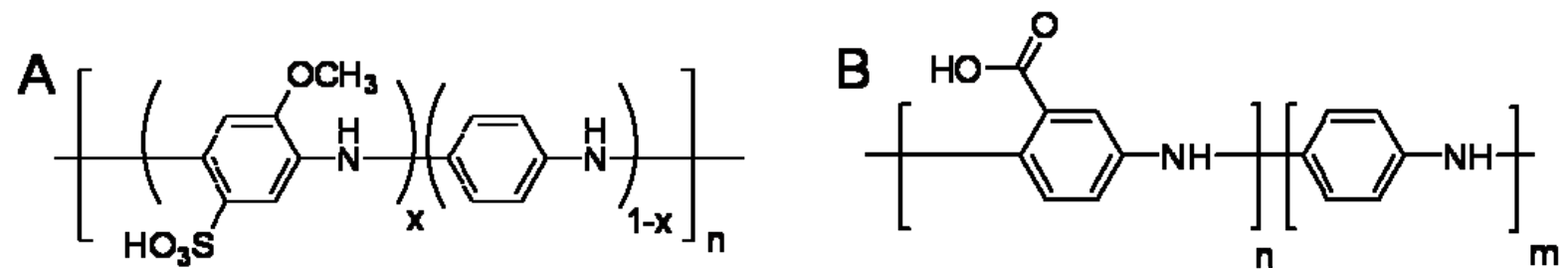

Scheme 1. Chemical structures of poly(2-methoxyaniline-5-sulfonic acid)-co-aniline [PMSA1] (A) and poly(3amino-benzoic acid)-co-aniline $[P A B A](B)$. The monomers have a statistic distribution in the molecules.
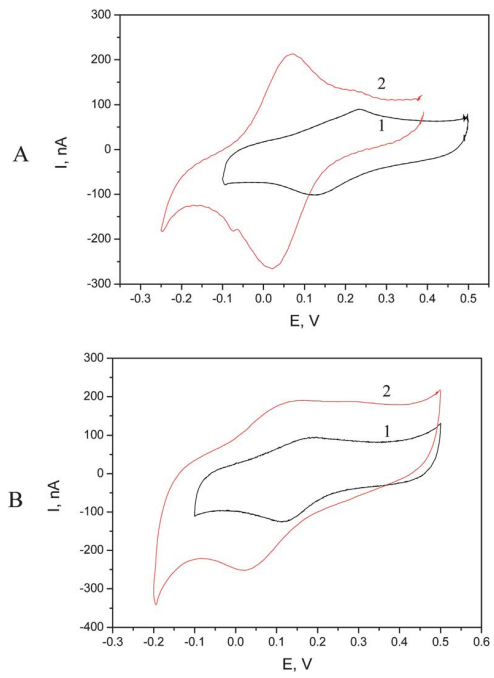

Figure 1. CVs of an immobilized layer of cyt $c$ on (A) PMSA1-coated and (B) PABA-coated polymer electrodes (gold wires). The curves indicated with (1) and (2) are CVs of polymermodified electrodes measured in buffer without cyt $c$ and with cyt $c$, respectively. Measurements are done in $5 \mathrm{mM}$ potassium phosphate buffer, $\mathrm{pH} 7$, scan rate $100 \mathrm{mV} \mathrm{s}^{-1}$.

field. The redox switching between oxidized and reduced states of sulfonated polyaniline is visualized not only in solution, but also with the thin polymer film on an ITO electrode surface by UV-Vis spectroscopy.

\section{Conclusion}

The enzymatic system induces redox switching between oxidized and reduced states of sulfonated polyaniline. This can be visualized not only in solution, but also with the thin polymer film on the electrode surface. The design of such simply prepared electrodes provides thus a new type of redox catalyst system for electron transfer to proteins, acting as a signaling element [3].

\section{Acknowledgements}

Financial support by the BMBF, Germany (project: 02IS2201I) is gratefully acknowledged.
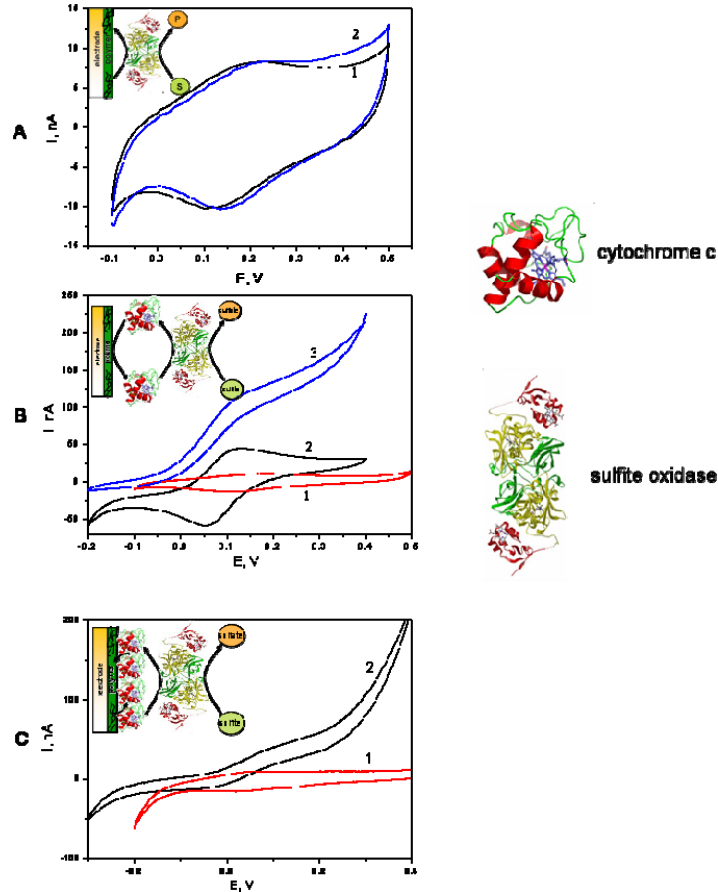

Fig. 2. CVs of PMSA-coated electrodes with sulfite oxidase: $A$ ) in the absence of cyt $c$ in solution [1 - CV of PMSA and SO, 2 - after addition of sulfite]; $B$ ) in the presence of cyt $c$ in solution [1 - CV of PMSA1 and SO, 2 - after addition of cyt c, 3-after addition of sulfite]. C) PMSA-cyt c-coated electrodes in the presence of the enzyme and substrate in solution Insets: schematic presentation of the process studied. Experimental conditions: $[\mathrm{SO}]=1 \mu \mathrm{M},[\mathrm{cyt} \mathrm{c}]=$ $100 \mu \mathrm{M}$, [sulfite] $=1 \mathrm{mM}, 5 \mathrm{mM}$ potassium phosphate buffer at $\mathrm{pH} 7$, scan rate $5 \mathrm{mV} / \mathrm{s}$.

\section{References}

[1] Wallace, G., Kane Maguire, L. A. P. Advanced Materials. 2002, 14, 953-960. DOI: 10.1002/1521-4095(20020705)

14:13/14<953::AID-ADMA953>3.0.CO;2-T

[2] Ge, B., Lisdat, F. Anal. Chim. Acta. 2002, 454, 53-64. DOI: 10.1016/S0003-2670(01)01545-8

[3] Sarauli, D., Xu, C., Dietzel, B., Stiba, K., Leimkühler, S., Schulz, B., Lisdat, F. Soft Matter, 2012, 8, 3848-3855 DOI: 10.1039/C2SM07261K 